\title{
The Effect of Lamium album and Lamium purpureum Extracts on Some Blood Parameters under Anakinetic Stress Conditions in Wistar Rats
}

\author{
Ioana ROMAN*, Constantin PUICĂ, Vlad TOMA \\ Institute of Biological Research Cluj-Napoca, Branch of N.I.R.D.B.S., Bucharest, Romania \\ * Corresponding author: ioana.roman@icbcluj.ro \\ Bulletin UASVM Veterinary Medicine 73(1) / 2016, \\ Print ISSN 1843-5270; Electronic ISSN 1843-5378 \\ DOI:10.15835/buasvmcn-vm: 10902
}

\begin{abstract}
The 17 days subcronic anakinetic stress induced to white Wistar rats by immobilization and darkness has determined TGO, cholesterol and triglycerides values increase, and serum creatinine decreases. Lamium album vegetable extract administration significant increases triglycerides and GOT values and decreases serum creatinine. Administration of both L. album and L. purpureum extracts, in terms of exposure to anakinetic stress, has resulted in a significant increase of the liver transaminases and triglycerides level, decrease of cholesterol and rise of serum creatinine levels. Administration of Lamium purpureum (LP group) vegetable extract has induced the increase of triglyceride values and decrease of cholesterol and serum urea levels. In the SLA group, there was an increase in the red blood cells (RBCs), hematocrit and platelet number, vs. the control group. It has also experienced an increase of the platelets in other treated groups. In the SLP group was noted an increase in the RBCs, hematocrit and platelet number vs. the control group and the decrease in the number of lymphocytes. In conclusion, the vegetal extracts of L. album and L. purpureum (20 mg/100 g b.w.), induced protective modulatory effects on the dynamics of the entire set of functional analyzed parameters.
\end{abstract}

Keywords: blood parameters, Lamium album, Lamium purpureum, Wistar rat

\section{INTRODUCTION}

Anakinetic prolonged stress induces the formation of reactive oxygen species (ROS), hydrogen peroxide and other reactive species of free radicals, which causes peroxidation of the lipids, especially at the cell membranes level, with destructive effects on all tissue. (Nayanatara et al., 2012). Herbs and other plants that contain more polyphenols, natural antioxidants, are a category of plants sought because of their possible use in phytotherapy, in the prevention and treatment of the effects induced by ROS. Some of the most popular Lamium species in our country that have a medicinal use are: Lamium album L. and Lamium purpureum L.

L. album, white dead nettle, is commonly used in modern Western herbal medicine for hormonal dysfunction in women, but it also has very good effects in transit disorders and intestinal infections, in internal bleeding and in some diseases caused by poisoning. L. purpureum, red dead nettle contains essential oils (in the glandular hairs), mucilage, tannins and saponins. Because of this composition is used for its astringent, diaphoretic, diuretic, purgative and hemostatic properties.

\section{AIMS AND OBJECTIVES}

The aim of our research was to test the effects of the dead white/red nettle (Lamium album and Lamium purpureum) hydro alcoholic extracts, on some blood biochemical and hematological parameters, in conditions of anakinetic stress induction to white rat. 


\section{MATERIALS AND METHODS}

Experiments were performed on white female Wistar rats, weighing $165 \pm 20 \mathrm{~g}$, Animals were divided into 6 groups of 6 animals each, as follows: control group (C); anakinetic stressed group (S); $L$. album hydro alcoholic extract treated group (LA) (20 mg extract/100 g bw), á jeun; L. purpureum hidroalcoholic extract treated group (LP) $(20 \mathrm{mg}$ extract/100 g bw), á jeun; S + LA treated group (SLA) and S + LP treated group (SLP). Plant extracts were administered by gavage, for a period of 17 days. The hydro alcoholic extracts of L. album and L. purpureum was obtained at the "Stejarul" Biological Research Center, Piatra Neamț. The alcoholic extract (1:1) was obtained with alcohol $70^{\circ}$. Qualitative analysis of the polyphenolic compounds of the L. album and L. purpureum extract were done by thin-layer chromatography (TLC), spectrophotometry and high performance liquid chromatography (HPLC).

In the $18^{\text {th }}$ day, animals were killed by decapitation after a pre-anesthesia with ether. Blood was collected for biochemical and hematological parameters determination.

*Animals were obtained from the bio base of "Iuliu Hatieganu” MPU, Cluj-Napoca and kept under standardized zoohigienical conditions: in accordance to the ECC Directive (2010/63/UE) and according to the approval of the Ethics Committee and Animal Protection for Experiments from the Institute of Biological Research, NIRDBS branch, Cluj-Napoca, Romania, (Decision 1/28.02.2013).

\section{RESULTS AND DISCUSSION}

In stressed group (S) TGO, cholesterol and triglycerides values increase, and serum creatinine decreases. Lamium album (LA group) - plant extract administration significantly increases triglycerides and GOT values and decreases serum creatinine. Administration of both L. album and L. purpureum extracts, in terms of exposure to (SLA and SLP group), has resulted in a significant increase of the liver transaminases (TGP, TGO) and triglycerides level, decrease of cholesterol and rise of serum creatinine levels. Administration of Red dead nettle (LP group) plant extract has induced the increase of triglyceride values and decrease of cholesterol and serum urea levels. (Tab. 1).

In the SLA group, there was an increase in the red blood cells (RBCs) $(36.82 \%, p<0.05)$ and hematocrit $(+36.18 \%,<0.05)$, vs. the $C$ group. It has also experienced an increase in the hemoglobin and hematocrit level (statistically insignificant) and statistically significant increase of the platelets in other treated groups $(\mathrm{S},+19.77 \%, \mathrm{p}=0.02$ and $\mathrm{LA}$, $+23.96 \%$, $p<0.05$ ). In LP group RBCs number was increased with $33.19 \%(\mathrm{p}<0.05)$ and in the SLP group RBCs was increased with $33.76 \%(\mathrm{p}<0.05)$, and the lymphocytes number was significantly decreased $(-34.9 \%, \mathrm{p}<0.05)$ vs the $\mathrm{C}$ group.

GOT and GPT increased activity might be due to the alteration of cell membrane permeability, allowing the activity increase of these enzymes, (Nayanatara et al., 2012). Dead nettle extract causes a pronounced diuresis, leading to body dehydration, being followed by a number

Tab. 1. Biochemical parameters levels in anakinetic stress and Lamium album and Lamium purpureum treated rats (mean \pm S.E., Student " $t$ " test, significant from $\mathrm{p}<0.05$ )

\begin{tabular}{ccccccc}
\hline Group & $\mathrm{C}$ & $\mathrm{S}$ & $\mathrm{LA}$ & $\mathrm{LP}$ & SLA & SLP \\
\hline $\begin{array}{c}\text { Colest } \\
(\mathrm{mg} \%)\end{array}$ & $181.9 \pm 22.16$ & $\begin{array}{c}226.98 \pm 6.32 \\
0.1<\mathrm{p}>0.05\end{array}$ & $166.83 \pm 16.22$ & $\begin{array}{c}106.26 \pm 9.11 \\
\mathrm{p}<0.01\end{array}$ & $81.025 \pm 8.55 \mathrm{p}<0.001$ & $\begin{array}{c}102.81 \pm 42.24 \\
\mathrm{p}<0.01\end{array}$ \\
\hline $\begin{array}{c}\text { Trigl. } \\
(\mathrm{mg} / \mathrm{dL})\end{array}$ & $24.06 \pm 7.22$ & $53.88 \pm 16.84$ & $53.69 \pm 14.51$ & $\begin{array}{c}41.5 \pm 3.82 \\
0.1<\mathrm{p}>0.05\end{array}$ & $\begin{array}{c}50.85 \pm 5.16 \\
<0.05\end{array}$ & $\begin{array}{c}48.14 \pm 3.9 \\
<0.05\end{array}$ \\
\hline $\begin{array}{c}\mathrm{TGO} \\
(\mu \mathrm{gpyr} / \mathrm{ml} / \mathrm{h})\end{array}$ & $143.78 \pm 4.43$ & $\begin{array}{c}179.33 \pm 8.05 \\
\mathrm{p}<0.01\end{array}$ & $\begin{array}{c}172.48 \pm 8.93 \\
\mathrm{p}<0.05\end{array}$ & $165 \pm 14.21$ & $236.5 \pm 21.45 \mathrm{p}<0.01$ & $\begin{array}{c}179.72 \pm 7.68 \\
\mathrm{p}<0.01\end{array}$ \\
\hline $\begin{array}{c}\mathrm{TGP} \\
(\mu \mathrm{gpyr} / \mathrm{ml} / \mathrm{h})\end{array}$ & $282.24 \pm 9.76$ & $321.12 \pm 17.28$ & $274.8 \pm 47.04$ & $254.5 \pm 18.9$ & $422.4 \pm 22.51 \mathrm{p}<0.01$ & $316.8 \pm 166.5$ \\
\hline $\begin{array}{c}\mathrm{Urea} \\
(\mathrm{mg} / \mathrm{dL})\end{array}$ & $44.20 \pm 7.85$ & $44.58 \pm 3.66$ & $51.95 \pm 9.08$ & $24.8 \pm 7.38$ & $31.08 \pm 2.63$ & $41.15 \pm 5.63$ \\
\hline $\begin{array}{c}\mathrm{Creat} . \\
(\mathrm{mg} / \mathrm{dL})\end{array}$ & $0.62 \pm 0.04$ & $0.54 \pm 0.02$ & $0.54 \pm 0.01$ & $0.63 \pm 0.04$ & $0.72 \pm 0.03$ & $0.1<\mathrm{p}>0.05$ \\
\hline Note: mean \pm S.E. (standard error), Student "t" test, significant differences from $\mathrm{p}<0.05)$ & & $0.62 \pm 0.03$ \\
\hline
\end{tabular}


of changes, including hematological ones. It has been suggested that different forms of stress increase the cholesterol level by disturbance of synthesis and excretion rate (Champe and Harvey, 1994). It is a known fact that catecholamine's activate lipolysis in adipose tissue and increase the flow of free fatty acids in liver, where the synthesis and secretion of triglycerides is increased. Increased triglyceride levels may be due to diuretic and anti-inflammatory effect of the L. album extract (Nayanatara et al., 2015), which resulted in decreased plasma volume and increased concentration of triglycerides in the blood. Increase in serum creatinine level signify a mild impairment of kidney function due by profuse sweating (rats were kept in an enclosed containers for 2 hours), dehydration (the used extract proved to be a good diuretic), diarrhea, etc.

White dead nettle has effects against anemia of various origins (Chudnicka and Matysik, 2005). On the other hand, when the body is dried, it produces more hemoglobin, which normally tends to disappear when the body is well hydrated. In the 3 treated groups, especially in SLA group we consider that recorded changes may be due to the two reasons listed cumulatively. The numerical value of platelets increases more or less in the case of dehydration, anakinetic stress, etc. (Friedman,1980, Hutchison et al., 2011).

\section{Conclusions.}

Anakinetic stress induced increase of cholesterol and triglycerides levels, serum creatinine decreases, non-significant increase in the hemoglobin and hematocrit level and significant increase of the platelets.

Lamium album plant extract administration shows significant increases of triglycerides and GOT values and decreases serum creatinine. Low increase in the hemoglobin and hematocrit level and significant increase of the platelets were also registered.

Administration of both $L$. album and $L$. purpureum extracts, induced a significant increase of the liver transaminases (TGP, TGO) and triglycerides level, decrease of cholesterol and rise of serum creatinine levels.

Administration of L. purpureum plant extract induced the increase of triglyceride values and of RBCs number and decrease of cholesterol and serum urea levels.

Increase in the red blood cells (RBCs) and hematocrit was registered in anakinetic stress treated with L. album group vs. the C group.

In anakinetic stress treated with L. purpureum group significant increase of RBCs and significant decrease of the lymphocytes number were registered vs the $\mathrm{C}$ group.

The results of our study suggest that the vegetal extracts of $L$. album and $L$. purpureum at the concentration used in the study $(20 \mathrm{mg} / 100 \mathrm{~g}$ b.w.), induced protective modulatory effects on the dynamics of the entire set of functional analyzed parameters.

Acknowledgements: This article is based on work supported by the ANCS under grant number 09-36/13.02.2009 (Project 09-360.202/Phase II/2013 and Phase I/2014) to National Institute of Research and Development for Biological Sciences (NIRDBS), Bucuresti, Romania.

\section{REFERENCES}

1. Champe PC, Harvey RA (1994). Biochemistry, 2 ed, Lippincott-Raven Publishers, 47-60.

2. Chudnicka A, Matysik G (2005). Research of enzymatic activities of fresh juice and water infusions from dry herbs. Journal of Ethnopharmacology 99:281-286.

3. Friedman RB (1980). Effects of Diseases on Clinical Laboratory Tests. American Association of Clinical Chemistry.

4. Hutchison RE, McPherson RA, Schexneider KI (2011). Basic examination of blood and bone marrow. In: McPherson RA, Pincus MR (eds). Henry's Clinical Diagnosis and Management by Laboratory Methods, 22nd ed, Elsevier Saunders, Philadelphia,chap 30.

5. Nayanatara AK, Tripathi $Y$, Nagaraja $H$, Jeganathan $P$ (2012). Effect of chronic immobilization stress on some selected physiological, biochemical and lipid parameters in Wistar albino rats. Res J Pharm, Biol, Chem Sci 3(1):3442. 